\title{
EFFECTS OF SOCIAL NETWORKING MEDIA TO THE ACADEMIC PERFORMANCE OF THE STUDENTS
}

\author{
Remedios C. Kulidtod \\ Department of International Relations, \\ Institute of Middle East and Asian Studies \\ University of Southern Mindanao, Philippines \\ ayeshakulidtod@yahoo.com
}

\author{
Nahida S. Pasagui \\ nspasagui@yahoo.com
}

\begin{abstract}
Social networking media has been the major source of communication between individuals in the world over, hence, the label cyber-world. This includes Facebook, Twitter, MySpace, Instagram, Flicker, Frienster, Blogs, Podcast, Youtube, Tumblr and Skype, among others. Users of these forms of media made use of such technology gadgets as cell phones, tablets, laptops, desktop computers, and e-readers. Researchers all over the world have varied findings on the effects of these forms of media on the academic performance of students. Those students who used the media wisely, their academic performance improved. However, those who failed to regulate their use of these social networking tools negatively affected their studies which oftentimes led to their addicted use. In general, the study found out that the exposure of the IMEAS students to the social networking media positively affected their academic performance. Hence, the University must implement policies and projects designed for more easy access of the students to the Facebook network site in the school campus. In contrast, there is also this very disturbing finding of the study which disclosed that the students of IMEAS, University of Southern Mindanao, Kabacan, Cotabato used the social networking media almost daily since majority of them answered to have used said form of media 5-6 days a week at an average of about 1-2 hours every session. With this data, it is recommended that the USM must regulate the proper time usage by the students of social networking media in the campus in order not to destruct with their classroom activities.
\end{abstract}

Keywords: social networking, social networking media, social learning theory, internet/websites, academic performance

\section{INTRODUCTION}

Social networking media is about sharing or communicating with other people. It has spread its wings to various other fields and education is one of the new sectors where the concept of social media is making a great role (Anonymous, 2014). They are communication channels or tools used to store, aggregate, share, discuss or deliver information with friends and colleagues using the internet (Reynolds, 2015). They involve the use of web-based technologies to transform one-way communication into an interactive online dialogue (Dixon, 2012). It is a creation and exchange of user-made content. At school or in any office, social media used by students and teachers to share original content the articles or the publications. Students, in particular, use it and provide an opportunity to seek to questions they may have related to their course. Thus, the use of social media has extended throughout the community (Roblyer, et al., 2010).

In the previous years, social media websites have become common. It gives young people a new way to interact with each other and communicate with the world. Social media networking became popular between 2004 and 2006, after Facebook and MySpace were created. Facebook, for example has over 500 million members and it is still growing and approximately $85 \%$ of undergraduate students are Facebook users (Schneider, 2009). During the second quarter of 2008, 75\% of Internet surfers used "Social Media" by joining social networks, reading blogs, or contributing reviews to shopping sites. This represents a significant rise from $56 \%$ in 2007 . The unlimited growth is not only limited to teenagers or to one of the members of Generation X. Today, 35 - 44 years old people have increasingly joined the population and counted as joiners, spectators, and critics. Therefore, it is reasonable to say that social media represent a revolutionary new trend that should be of interest to companies operating in online space - or any space, for that matter (Kaplan \& Haenlein, 2010).

As we know, the new social media include internet websites such as MySpace, Facebook, Twitter, Flicker, and other social networking or social media, and sharing sites, as well as blogs, video games, virtual worlds, mobile telephones, text messaging devices and Global Positioning System (GPS) devices. It includes blogs (political Blog), networks (Facebook, Twitter, etc), video sharing (YouTube), audio sharing (Podcast), mobile sites (2go etc), image or picture sharing (flicker), etc. It has the capacity to improve the participation because of the textual and audio-visual characteristic appeal, the openness, conversation nature, and connectedness (Adaja, 2013).

In August 2015, the statistics ranked and provided information on the most popular networks worldwide by a number of active accounts. The first social network was Facebook as it surpassed 1 billion registered accounts. The micro blogging network, Twitter, ranked tenth and it had over 316 million monthly active accounts while the blogging service, Tumblr, had more than 230 million active blog users on their site. The leading social networks are usually available in multiple languages and enable users to connect with friends or people across geographical, political or economic borders. In 2012, more than 1.4 billion internet users accessed to social networks and these figures are still expected to grow as mobile device usage and mobile social networks increasingly gain traction (Anonymous, 2014).

Hence, one cannot overemphasize the growing dimension of the use of the social media among the youth of today. Social networking media have become more and more popular to the second cycle students 
over the past years. They have helped many people feel as if they belong to a community and make connection not only on campus but with friends outside of school. Due to the increased popularity of social networking media, economists and professors are requesting the clientele to go to different websites for efficient paper works ignoring how much time spent on these different sites (Choney, 2010).

Moreover, college students nowadays (which consist of Baby Boomers, Generation Xers, and Millenials) are exposed to all types of technologies in many aspects of their live and form of large proportion of users on social media networks such as Facebook, Twitter, Instagram, MySpace and many more (Guy, 2012). In particular, in the University of New Hampshire, the students use Facebook and YouTube than any other social media platform. Blogs, Twitter, MySpace, and Linkedln had significantly lower amounts of student users. The students from the business school had the highest percentage of users of blogs, Twitter, and Linkedln while Liberal Arts students were the highest percentage of My Space users (Martin, 2013).

With the above data, one could say that social networking media sites have become a habit for some students and it was found out that it is difficult for them to study for one hour without logging in to one network site. They become very smart because of the information they get from these sites and it easy to get almost any materials for school assignment. But some students become very poor academically (Egedegbe, 2014). According to the research of Brubaker (2013), the current generation of college students has been exposed to a technology which led them to rely on social media such as Facebook and Twitter. It has an impact on the academic performance when students overuse or multitask while doing their school work.

A study found out that $90 \%$ of college students visit social media networking sites in a regular basis using desktop computers, laptops, e-readers, tablets, and cell phones to actively engage in social networking, text messaging, blogging, content sharing, online learning, and much more daily (Guy, 2012). As an effect, most of the users have the good quality of communication skills through the use of social networking media over the computer [Sponcil and Gitimu (n.d.)]. They were able to communicate with friends and family by posting information and they spent much of the time viewing information. The faceto-face interactions via the computer facilitate communication which allows users to keep in touch with family and friends in a convenient way and to learn about social events and issues.

Said finding was corroborated by the work of Anonymous (2014) who maintained that creating Facebook Group has good effects to the students. They can share topics online. Study groups and students can use it to connect with each other outside of the classroom while the bad effect is that students may want to add as friends to make trouble or some personal reasons. Also, the students can also access to a world of knowledge through the use of social networking media and other forms of digital communication. Slaughter (2007) said that social networking media have deeply transformed the learning. When students are connected to social networking media it will helps them to earn better grades at school (Skiera, Hinz \& Spann, 2015).

In studying the total number of hours spent by the users, Wang, Chen and Liang (2011) disclosed that $45 \%$ of their samples admitted that they spent $6-8$ hours per day checking social media sites, while $23 \%$ spent more 8 hours; $20 \%$ spent $2-4$ hours and only $12 \%$ spent less than 2 hours on this task. Results showed that social media is a college interest in the Wales University. Students consume a lot of time on social networking sites especially the adolescents. They are involved in uploading/downloading, getting information related to their academic or future career, chatting with friends and watching online movies (Kanagarathinam, 2014). Twitter is one of the most important media companies in the world. It is now one of the top 10 most visited sites. With more than 500 million users, the students can find teachers, schools, and perhaps more important professionals, lead publications in their areas of interest (Anonymous, 2013).

Blogs can be used in classroom environment for diary entry; it also can be a useful tool to link communication between study groups within a class or other classes or even schools. Blogs can highly motivate the students, especially those who otherwise might not become participants in the classrooms. It gives excellent opportunities for students to read and write effective forums for collaboration and discussion, and powerful tools to enable scaffolding learning or mentoring to occur (Nguyen, 2015). According to the study of Head and Eisenberg conducted in 2009, Wikipedia provides the students with a summary about a topic, the meaning of related terms, and also got students started on their research and offered a usable interface and one of the expectable workarounds that many students use, especially during the first stages of their research process. In University of Washington's Information School, most of the college students use Wikipedia and they know its limitation. Because of its quick way to get started, they use Wikipedia just as most of people do but not deep and credible.

In other words, knowledge on the social networking media is a basic asset that a college student nowadays must possesses in order to survive in his chosen volition. In this regard, a question may be asked: Is any use of social networking media beneficial to students? Unfortunately, studies revealed different results. Accordingly, the use of technology such as internet is one of the most important factors that can influence educational performance of students positively or adversely. The effect of SNS usage will depend on the type of SNS the student is using, if student uses the internet for the purpose of leisure activity that interferes with academic, it will affect the student academic performance negatively (Egedegbe, 2014). According to the study of Tayseer, et al., (2014), result showed that most of the students who spend many hours in using social networks have a high GPA at the Petroleum University. 
In short, social media has several effects on academic work, some are more positive than others. But with around $96 \%$ of all college students on Facebook, only the most dedicated academics would consider giving up social media for a slightly better GPA. Also, social media may have a positive impact on students' sense of themselves in the community. Social media-using students were twice as likely as other students to feel well-liked by their peers and to participate in extracurricular activities. However, negative effects abound.

Students who use social networking media sites and hit the books simultaneously found their multitasking led to $20 \%$ lower grades that those of their more focused peers. It also made less money during school from part-time work, putting in around five hours per week as opposed to 16 hours per week for a typical, unplugged counterpart (O'dell, 2011). According to the research of Ferrer conducted in 2013 at the University of Southern Mindanao, 93.8\% of Bachelor of Arts in English was a member of social media networking and $48.94 \%$ got an excellence General Point Average.

A particular study by Kumar (2014) revealed that social networking media gave a sense of belonging to an academic community, as the students online with their friends were mostly they met in college. Two step flow interactions, student to student and teacher to student favored academic learning through social networks. The use of these networks has to be disciplined as it can lead to distraction from education. The social networks used for educational tutoring and social networking sites that students used for academic purposes are the YouTube, WhatsApp and Facebook. Meanwhile, not only the students are benefiting. For example, the National Association for College Admission Counseling (NACAC) discovered that $85 \%$ of college admission offices reported using at least one form of social media to recruit prospective students in 2008 and increase from 61\% last 2007 (Anonymous, 2014)

In sum, we can say that there are benefits and risks associated with using any social network even though there have been reports regarding its effect on students' academic performance. Accordingly, some researchers found a poor effect and influence when the media is overuse in such a way that do not academically improve learning or its process. There are still other researchers who examined this same problem but have found no conclusive data affirming the significant relationship between using social networking and student academic performance (AlRahmi and Othman, 2013).

Since available research data are inconclusive of the effects of social networking media on the academic performance of students, it is timely and an imperative necessity to study on whether or not the exposure to social networking media of the students of the Institute of Middle East and Asian Studies (IMEAS) of the University of Southern Mindanao (hereinafter referred to as USM), Kabacan, Cotabato can explain their high academic performance.

\section{Statement of the Problem}

This study was conducted to determine the effects of social networking media to the academic performance of IMEAS students. Specifically, it sought to answer the following questions: (1) What are the different types of social networking media subscribed by the scholar students of the IMEAS?; (2) What are the different types of IT gadgets commonly used by the respondents in accessing social networking media?; (3) What are the perceived effects of social networking media to the academic performance of the IMEAS students?; and (4) What is the relationship of the social networking media and the respondents' academic performance?

\section{Significance of the study}

The results of this study shall be beneficial to the school administration, the faculty, the students, and the public in general. To the University of Southern Mindanao (USM) officials, the results would guide them empirical bases in the improvement of the existing educational policies, curriculum and strategies, or the formulation new ones, towards a more effective delivery of learning in this information age.

To the curriculum committee and the academic affairs office, output of this research would provide them a first-hand information on how social networking media affects the academic performance of the students in the University, in general, and in the Institute of Middle East and Asian Studies (IMEAS), in particular, so that they would design measures to further improve, upgrade and expand the coverage of the internet service in the school campus. Further, for the guidance counselors, this study also gives them clear perspective on how the specific behavior of students is affected by social networking media. To the IMEAS students, findings of this work shall guide them on how to properly design their study habits thereby improving their scholastic achievements. This will provide them information on how to exploit the use social media to improve their studies. To the future researchers on social networking media, the results would serve as a baseline data for them to conduct the same study in order to validate the findings.

\section{Scope and Limitation of the study}

Due to time and financial constraints, this study recognizes many limitations not only in terms of its scope and focus but also in its statistical tools, time frame, sampling methods, and others. On its scope and time-frame, it focused only on the effects of social networking media to the academic performance of IMEAS students who were officially enrolled in the First Semester, 2015-2016. Moreover, only basic statistics were employed since the study is descriptive in nature. Finally, the purposive sampling was employed in choosing the respondents of the study.

\section{Setting of the study}

The study was conducted in the Institute of Middle East and Asian Studies (IMEAS), University of Southern Mindanao (USM), Kabacan, Cotabato during the second semester of the academic year 2015-2016. 
Occupying a total land area of about 1,024 hectares, the University of Southern Mindanao (USM) is situated in Poblacion Kabacan, Cotabato which is about 600 meters away from the national highway. It is accessible by land transportation from any of the four main cities in Mindanao: 104 kilometers to Cotabato City, 143 kilometers to Davao City, 135 kilometers to General Santos City, and 196 kilometers to Cagayan de Oro City.

USM is claimed to be the pioneering landgrant University in southern Philippines. It was formerly given the name Mindanao Institute of Technology (MIT) which was founded by the late Bai Hadja Fatima Matabay Plang, the wife of former Senator and retired Brigadier General Salipada K. Pendatun, which became operational on October 1, 1954. It achieved a university status on March 13, 1978 by virtue of Presidential Decree No. 1312 signed by then President Ferdinand E. Marcos. At present, the University is consisting of nine (9) colleges and two (2) institutes, including the Institute of Middle East and Asian Studies (IMEAS). At present, the Institute is consisting of only two (2) academic departments, viz: International Relations and Islamic Studies. In the First Semester, 2015-2016, the former had one-hundred eighteen (118) enrolees while the latter had ninehundred nineteen (919).

\section{RESEARCH DESIGN AND METHODOLOGY}

In general, this study employed a descriptive research design which made use of both the primary as well as the secondary data. In trying to look for the perceived effects of social networking media of the respondents to the academic performance of the IMEAS students, the study used a questionnairemethod. The second type of data was gathered from written materials available in the different libraries in the University as well as those found on-line. Moreover, correlation analysis was used to interpret the relationship of the socio-demographic characteristics of the respondents and the effects of social networking media to their academic performance.

\section{Respondents of the study}

The respondents of the study were the ninetyone (91) students from the IMEAS who were taken as samples from the one thousand and thirty-seven students who were officially enrolled in the first semester of the school year 2015 - 2016. They were chosen using the Slovin's formula as follows:

$$
n=\frac{N}{1+N_{e}^{2}}
$$

Where:

$\mathrm{N}=$ Population

$\mathrm{n}=$ sample size

$\mathrm{e}=$ Marginal error $(10 \%)$

Computation:

$n=\frac{1,087}{1+1,307_{(107)}^{2}}$

$$
\begin{aligned}
& n=\frac{1.037}{1.37} \\
& n=91
\end{aligned}
$$

\section{Sampling Procedure}

Three types of sampling methods were used in this research. The first is the purposive/selective sampling, which is employed in the choice of the respondents considered in the study. As previously mentioned, the student-respondents are selected due to their most accessibility. Proportionate stratified random sampling was employed in getting the prescribed total number of respondents from the two sample academic departments, that is, 81 from the Islamic Studies Department while only 10 from the International Relations Department. The third and the last type of sampling method is the systematic random sampling which is employed in the selection of the respondents from the list of enrolees available in the Institute. This is done by selecting the names of the respondents from the list of enrolees by having five interval names for every draw until the desired total number of respondents from every Department had been chosen.

\section{Research Instrument}

In gathering the primary data, the only instrument used in this research was a structured questionnaire. It consisted on two parts. Part 1 contains the socio-economic profile of the respondents while Part 2 comprises questions regarding the description of social networking media of the respondents and its perceived effects to the academic performance of the students.

\section{Data Gathering Procedure}

First, the researchers sent a letter addressed to the USM President through the registrar asking approval to get the Grade Point Average of the students and to IMEAS dean for the conduct of the study. Second, the researchers conducted administered the pretesting of the questionnaire for validation of the said instrument. Third is the sampling and actual identification by the researchers of the actual respondents. Questionnaires were retrieved right away after the respondents have answered them all.

\section{Statistical Analysis}

The statistical tools used in the study were the descriptive statistics such as percentage, frequencies, and averages. Furthermore, Pearson-coefficient tool was used to determine the relationship of the sociodemographic profile of the respondents and the perceived effects of social networking media to the academic performance of the respondents.

\section{FINDINGS AND CONCLUSIONS}

For the socio-demographic profiles of the respondents, it was revealed that most of the respondents were at the age of 18 to 20. This confirms the claim by Lennon, Rentfro, and Curran (2012) that the young adults whose ages range from $18-20$ oftentimes use social networking sites compared to 
those belonging to the higher age brackets. In terms of sex, the study gathered that female respondents dominated the samples who constituted $81.32 \%$ of them. This is not surprising since nowadays, the women out numbered men and there is a numerical difference between the two sex's increases with age. In France, eight centenarians in ten are women (Anonymous, 2015).

Moreover, greater of the respondents were single whose monthly incomes range 500 to 1000 weekly which came out in form of living allowances. As to the access of students to social media networking sites, the study revealed that the respondents availed of the following social media networks (in descending order): (1) Facebook, (2) Twitter, (3) MySpace, (4) Instagram, (5) Flicker, (6) Frienster, (7) Blogs, (8) Podcast, (9) Youtube, (10) Tumblr and (11) Skype. This finding corroborated the data in a research that Facebook now has more than 1.5 billion users, more than 1 billion of which use the service daily in the first quarter of 2015. It was revealed that Facebook has passed 1.55 billion monthly active users and 1.39 billion are mobile users. As of last year, Facebook also shared that it had a 1.01 billion daily active users and 894 million mobile daily active users (Protalinski, 2015). This may imply that Muslim students of the Philippines also follow with the social network trend in the world over.

In accessing these networks, the respondents used the following information gadgets (in rank order): (1) cell phones, (2) tablets; (3) laptops; (4) desktop computers; and (5) e-readers. The students of the Institute used the social networking media for the following purposes (in rank order): (1) to like the post of their friends, topics and etc.; (2) downloading; (3) chatting; (4) uploading pictures, writings, etc.; and (5) post comments to friends. This is found supportive to the finding of a study by Fox News' Dr. Manny that teenagers used their social networking media accounts to likes, comments and follow and they base their selfworth on the number of likes, comments and followers they obtain from it (Talreja, 2013). Although, all the respondents were students but this data show that they were not fully using their social media activities for academic purpose but for social purpose, like connecting with friends.

Furthermore, aside from the enumerated purposes above, the respondents used the social networking media due to the following reasons (in rank order): (1) to communicate with people who are away from them; (2) to be updated with latest news; (3) to gain knowledge for academic purposes; (4) for pleasure and fun; and (5) and other similar reasons. This finding validates the above output that studentusers of the Facebook are spending much of their time for social purposes. On the question of frequency of their use of social media, it was revealed that studentrespondents used the social networking media almost daily since majority of them answered to have used said form of media 5-6 days a week at about 1-2 hours every session. According to the survey conducted in $2013,63 \%$ of the students check their social networking media sites at least once a day and the $33 \%$ who check 6+ times a day (Anonymous, 2014). This means that much of the time of the respondents was spent in the internet usage rather than in their class activities.

On the perceived effects of social media network to the respondents, the data disclosed the following (in rank order): (1) helps them to become updated on current issues and events that can help on their studies; (2) helps them to improve their communication skills; (3) helps them to share topics online; (4) gives them information related to their academic or future career; (5) helps them to find answers for their school works; (6) helps them to become smart because of the information they get from the sites; (7) gives them an excellent opportunity for effective forums in class discussion; (8) helps them to earn better grades in school, (9) helps them to improve their participation in school; and (10) highly motivates them to become participative in the classroom with $56.04 \%$ of the IMEAS students. This output may imply that the main purpose of the students in using internet is different from their actual activity whenever they already accessed the sites. While their common main objective of accessing the networks was for academic purposes (i.e., to communicate with people who are away from them) but in practice they were using their internet time for social purposes (i.e., to like the post of their friends, topics and etc.).

Finally, as to the relationship of selected socio-demographic characteristics and academic performance of the respondents, the study found out that only sex was significantly related to the social network media and to the academic performance. This means that female students of the Institute were more exposed to the social networking media than the males. As an effect, their academic performance is much better as compared to the male students who seldom used said form of media. This is similar with the findings of Lennon, Rentfro, and Curran (2012) who maintained that women are more likely than men on the social networking media sites. Women are joining social networks even if they got married, but married men joined the social networking media only occasionally.

\section{RECOMMENDATIONS}

First, the USM, in general, and IMEAS, in particular, must implement policies and projects designed for more easy access of the students to the Facebook network site in the school campus. However, part of the said project must incorporate policies that must regulate the proper time usage by the students in order not to intervene with their classroom activities. Moreover, making the in-campus internet access available for every student shall make them safer in accessing as compared to availing the same service outside the campus during evening time.

Second, the USM must modify its academic curricula to incorporate more subjects on information technology in all baccalaureate degrees to make their graduates more competitive in the world market. Further, this educational policy may also help the students to gain appropriate knowledge from their 
professors on how to use wisely their time in the social networking so as not to affect their academic activities. Third, there must the proper and regular monitoring of parents in the use of the social network media by their children to protect them from obscenity, pornography, internet bullying and addiction which tendencies may seriously affect their studies.

Fourth, the students of the IMEAS, especially those who are slow learners, must exert more efforts on how to use and exploit all the available avenues of social networking media in order to compete with their fast-leaner classmates. Finally, it is further recommended that similar but more intensive study on the relationship of the social networking media and academic performance of students be conducted. This study, being limited in scope, objectives, purposes, tools and statistical methods used, needs to be deepened, broadened and expanded to include all the other academic units of the USM, if not all the universities in the entire Philippines, in order to analyze comprehensively and understand exhaustively the more encompassing aspects of the social networking not only in the University under study but in the context of the entire country as well.

\section{REFERENCES}

[1] Adaja, T. (2013). Nigerian Youths and Social Media: Harnessing the Potentials for Academic Excellence. Olabisi Onabanjo University Ago-Iwoye, Ogun State Nigeria, pp. 59.

[2] Ainin, S., Naqshbandi, N. M., Moghavvemi, S., Jaafar, N. I. (2015). Facebook Usage, Socialization and Academic Performance. Computers \& Education, 83, 64-73.

http://dx.doi.org/10.1016/j.compedu.2014.12.018

[3] Al-Rahmi W. and Othman M. (2013). The Impact of Social Media use on Academic Performance among University Students: A Pilot Study, Universiti Teknologi Malaysia, 81310 Skudai, Johor, Malaysia. pp. 1-10.

[4] Bandura, A. (1997). Self-Efficacy: The Exercise of Control. New York, NY: Freeman.

[5] Brian, D. (2012). Social Media for School Leaders: A Comprehensive Guide to Getting Most out of Facebook, Twitter and other essential Web Tools, pp. 1.

[6] Brubaker, E. (2013). The Relationship between Facebook Activity and Academic Performance among African American Students. Liberty University, Lynchburg, VA, pp 30 and 22.

[7] Egedegbe, N. (2014). Academic Oerformance in Girne American University. North Cyprus. pp. 1-11.

[8] Ferrer, J. (2013). Social Networking Practices and students General Academic Performance. University of Southern Mindanao, Kabacan, Coatabato.

[9] Guy, R. (2012). The use of Social Media for Academic Practice: A Review Related Literature. Tennessee State University, rguy@tntate.edu, pp. 2-8.

[10] Kadushin, C. (2004). Introduction to Social Network Theory. pp. 1-63.

[11] Kanagarathinam, M. (2014). Impact of Social Networking Sites on Academic Performance of Adolescents in Coimbatore City. Nehru Arts and Science College Tamilnadu, India, pp. 1.

[12] Kplan, A.M., \& Haenlein, M. (2009). Users of the World, Unite. The Challenges and Opportunities of Social Media, pp. 59.
[13] Kumar, K. N. (2014). "The effects of Social networking sites on the academic performance of students in college", pp. 1-21.

[14] Tayseer, M. et al, (2014). Social Network: Academic and Social Impact on College Students, The Petroleum Institute, Abu Dhabi, United Arab Emirates. pp. 1-5.

[15] Wang, Q., Chen W. and Liang, Y. (2011). The effects of Social Media on College Students, Wales University, UK. pp. 2.

[16] Yu, A. Y., Tian, S. W., Vogel, D., and Kwok, R. C. (2010). Can Learning be Virtually Boosted? An Investigation of Online Social Networking Impacts. Computers and Education, 55(4), 1494-1503. 